\title{
Thyroxine Absorption Test
}

\author{
Khaled Aljenaee ${ }^{1}$, Sulaiman Ali ${ }^{2}$, Seong Keat Cheah ${ }^{1}$ and John H McDermott ${ }^{1}$ \\ ${ }^{1}$ Department of Endocrinology, Connolly Hospital, Ireland \\ ${ }^{2}$ Department of Endocrinology, Mater Hospital, Ireland
}

Received: March 13, 2018; Published: March 22, 2018

*Corresponding author: Khaled Aljenaee, Department of Endocrinology, Connolly Hospital, Blanchardstown Dublin 15, Ireland, Tel: +353838632580; Email: k.jenaee@gmail.com

\begin{abstract}
Poor compliance with Levothyroxine therapy leading to apparently 'resistant' hypothyroidism, termed 'pseudomalabsorption', is a common clinical conundrum.. A thyroxine absorption test may aid clinicians in confirming suspected poor compliance with greater objectivity, but there is a lack of uniformity in practice and interpretation of this test. We herein report a case of suspected pseudomalabsorption where a thyroxine absorption test helped to confirm the diagnosis. A 29-year-old female was diagnosed with primary hypothyroidism in 2009 with TSH at diagnosis of 180 microIU/L. Euthyroidism was achieved by Levothyroxine administration, which was gradually increased to $175 \mathrm{mcg} / \mathrm{day}$. In the subsequent 2 years, however, she remained persistently hypothyroid despite doses of Levothyroxine well exceeding her estimated weight adjusted requirement. A thyroxine absorption test was performed, where once weekly directly observed administration of a weight-adjusted dosage of levothyroxine was performed over a consecutive 4 week period. TSH fell from a baseline of 18 microlU/L to 0.8 microlU/L in the fifth week. This finding confirmed pseudomalabsorption and excluded the need for a potentially exhaustive search for an organic underlying cause for the persistently elevated TSH.
\end{abstract}

Keywords: Hypothyroidism; Non-compliance; Malabsorption

\section{Introduction}

Primary hypothyroidism is the most common cause of hypothyroidism, and typically responds well to oral Levothyroxine replacement therapy. Factors interfering with Levothyroxine absorption such as co-ingestion of foodstuffs and/or medications, or underlying gastroenterological conditions such as celiac disease, can result in apparent resistance to Levothyroxine therapy - with difficulty achieving a normal TSH and a requirement for high doses of levothyroxine. Poor compliance with Levothyroxine, if denied by the patient, can present with a similar clinical picture hence the term 'pseudomalabsorption' has been applied in such cases. In the scenario where pseudomalabsorption is suspected, but is refuted by the patient, a breakdown in the therapeutic relationship between the patient and the treating physician can easily develop. By providing objective evidence of the presence or absence of levothyroxine malabsorption under controlled conditions the Thyroxine absorption test may aid clinicians in establishing poor compliance with relative objectivity and confidence, and can potentially restore the therapeutic relationship. Confirming a diagnosis of pseudomalabsorption using the Thyroxine absorption test may also negate the need for an exhaustive search for other causes of malabsorption or resistant hypothyroidism, and can also justify lowering of the often excessively high thyroxine dosage.

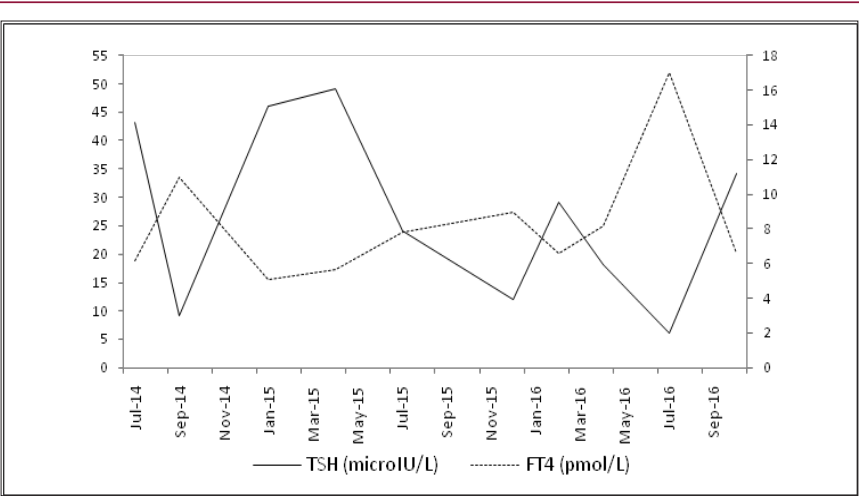

Figure 1: TSH (microIU/L) and free T4 (pmol/L) measurements over the period July 2014 to October 2016. 


\section{Case Report}

A 29 year old female was diagnosed with primary hypothyroidism in 2009, when she presented with symptoms of hypothyroidism, easy fatigability, excessive sleep, hair and skin dryness, and weight gain. Her TSH at diagnosis was 180 microIU/L (0.5-5 microlU/L), free T4 was $4.5 \mathrm{pmol} / \mathrm{L}(9-22 \mathrm{pmol} / \mathrm{L})$ and TPO Antibodies strongly positive. She was initiated on Levothyroxine $75 \mathrm{mcg} /$ day and subsequently achieved euthyroidism when

\begin{tabular}{|c|c|c|c|c|}
\hline Visit date & TSH (microIU/L) & Free T4 (pmol/L) & Body weight In kilogram & Weight adjusted Levothyroxine dose (mcg/kg) \\
\hline Apr-16 & 18 & 8.2 & 80 & 2.81 \\
\hline Jul-16 & 6 & 17 & 79 & 3.32 \\
\hline Oct-16 & 34 & 6.6 & 81 & 3.43 \\
\hline
\end{tabular}

This biochemical picture was in accordance with her complaints of persistent hypothyroid symptoms, reduced daily activity due to easy tiredness, and difficult to lose weight (Table1). She did not manifest any signs and symptoms of malabsorption. She reported taking her tablets in the early morning on an empty stomach. She was not any other medications, making medication interference with Levothyroxine absorption unlikely. Laboratory parameters as a rudimentary screen for malabsorption were essentially normal: her hemoglobin was $12.6 \mathrm{~g} / \mathrm{dL}(12.3-15.3 \mathrm{~g} / \mathrm{dL})$, albumin $43 \mathrm{~g} / \mathrm{l}$ (35-55 g/l), 25-hydroxy vitamin D $59 \mathrm{ng} / \mathrm{mL}$ (20-100 ng/mL), and calcium $2.4 \mathrm{mmol} / \mathrm{L}(2.10-2.60 \mathrm{mmol} / \mathrm{L})$, and anti transglutaminase antibodies were not detected. With careful explanation and with consent from the patient, a thyroxine absorption test was conducted. The patient attended the Endocrinology outpatient on consecutive Mondays for 4 weeks to have a directly-observed intake of her estimated weight-adjusted replacement weekly dose of Levothyroxine (applying the formula of [ weight $(\mathrm{kg}) \times 1.6 \mathrm{mcg} /$ $\mathrm{kg} /$ day x 7 day ], with her weight measured at $80 \mathrm{~kg}$, the weekly weight-adjusted Levothyroxine dose requirement was estimated to be $900 \mathrm{mcg})$.

Thyroid function testing was performed at baseline prior to the first observed dose and on the Monday of the fifth week, a week after the last observed dose. Baseline TSH was 18 microIU/L, and free T4 was $6.6 \mathrm{pmol} / \mathrm{L}(9-22 \mathrm{pmol} / \mathrm{L})$. On the fifth week of the test, TSH had normalized with a reading of 0.8 microIU/L and free T4 was also normal at $15 \mathrm{pmol} / \mathrm{L}$. With this objective result, we concluded with confidence that the persistent hypothyroidism in this patient was related to poor compliance with Levothyroxine therapy. This was explained to the patient who was relieved to find that there were no treatable organic causes for such derangement, and that a further search for a cause was not needed. A lower Levothyroxine dose was also justified in light of this test result, and the patient was prescribed $125 \mathrm{mcg} /$ day of Levothyroxine, an approximately $50 \%$ reduction in her prior prescribed dose. Her repeat TSH after 6 weeks on this lower dose remained in the normal range at 1.2 microIU/L.

\section{Discussion}

Primary hypothyroidism accounts for more than 90\% of cases of hypothyroidism and oral Levothyroxine replacement of

Levothyroxine was titrated to $175 \mathrm{mcg} /$ day. In 2011 she delivered a healthy boy uneventfully with TSH within target limits while on similar dosages. Between January 2014 and October 2016, however, her TSH remained persistently elevated, despite increasing Levothyroxine dosage (Figure 1). She was subsequently referred to Endocrinology clinic. At her first clinic visit we noted that the patient remained persistently hypothyroid despite being on Levothyroxine doses of $250-275 \mathrm{mcg} /$ day (Table 1 ).

$1.6-1.8 \mathrm{mcg} / \mathrm{kg} /$ day restores a euthyroid state in the majority of patients if taken function tests appropriately and absorbed into the bloodstream. As shown in Table 2, however, many conditions or coexisting medications can lead to interference with absorption of Levothyroxine or a requirement for higher doses than are typically required. A persistent hypothyroidism even with levothyroxine dosage exceeding the usual weight-adjusted required dose may prompt further assessment of levothyroxine malabsorption and poor compliance, the later being a diagnosis of exclusion which is difficult to confirm as it is based on a patient's voluntary self-report. Generally, the adherence rate to therapy in patient with hypothyroidism is around 65\% [1] (Table 2). A Thyroxine absorption test is a useful tool to rule out malabsorption as a cause for a high Levothyroxine dose requirement or apparent 'resistance' to Levothyroxine in a single test with objectivity and confidence. An improvement in thyroid post-test essentially rules out thyroxine malabsorption and renders further investigations unnecessary.

Table 2: Causes of increase levothyroxine requirements in hypothyroid patients.

\begin{tabular}{|c|c|}
\hline $\begin{array}{c}\text { Causes of Increase Levothyroxine Requirements in Hypothyroid } \\
\text { Patients }\end{array}$ \\
\hline physiologic requirement for higher doses \\
\hline - & Pregnancy \\
\hline - & Estrogen therapy \\
\hline Drugs which increase catabolism of T4 \\
\hline
\end{tabular}




\begin{tabular}{|c|}
\hline - $\quad$ Cholestyramine or colestipol \\
\hline - $\quad$ Sucralfate \\
\hline - $\quad$ Aluminum hydroxide gels \\
\hline - Calcium carbonate \\
\hline - $\quad$ Sertraline \\
\hline - $\quad$ Raloxifene \\
\hline - $\quad$ Proton pump inhibitors \\
\hline Nephrotic syndrome \\
\hline Previous thyroid irradiation \\
\hline Food \\
\hline - $\quad$ Dietary fibre \\
\hline - $\quad$ Dairy products \\
\hline - $\quad$ Coffee \\
\hline - $\quad$ Milk \\
\hline
\end{tabular}

A normal test also justifies lowering the Levothyroxine dosage to predicted weight-adjusted requirement. With the lack of a standard protocol for the tests, many variations of the test exist, albeit all are based on the same underlying principle. Three main variations of the thyroxine absorption test exist, namely: the short thyroxine absorption test; the long absorption test; and the modified absorption test. These tests require 6 hours, 5 weeks and 5 days to complete respectively (Table 3 ). All versions of the test report good utility in distinguishing between malabsorption versus noncompliance $[2,3]$ (Table3). The long thyroxine absorption test was adopted in our scenario; the weekly dose administered in this test is well tolerated generally and in the absence of malabsorption the TSH is expected to fall (and normalize), although to a lesser extent compared to the daily dose [4-7]. In a trial of 12 hypothyroid patients, 7 who were assigned to daily Levothyroxine doses and 5 assigned to weekly doses, the mean serum TSH was 3.92 microIU/ $\mathrm{mL}$ and 6.61 microIU/mL respectively [8].

Table 3: Common used protocols of thyroxine absorption tests.

\begin{tabular}{|c|c|c|}
\hline Type & Duration & Protocol \\
\hline \multirow{5}{*}{ Short/rapid absorption test [4-6] } & \multirow{5}{*}{6 hours } & After an overnight fasting \\
\hline & & Administer $1000 \mu \mathrm{g}$ of LT4 \\
\hline & & Inspect of the oral cavity and observe behavior for 60 minutes post ingestion \\
\hline & & Measure TSH at 0,1 and 2 hours \\
\hline & & $\begin{array}{c}\text { Measure free } \mathrm{T} 4 \text { at } 0,30,45,60 \text {, and } 120 \text { minutes (up to } 240 \text { minutes in some } \\
\text { protocols) }\end{array}$ \\
\hline \multirow{5}{*}{ Long absorption test [7] } & \multirow{5}{*}{5 weeks } & After an overnight fasting \\
\hline & & Administer a dose of $1.6 \mu \mathrm{g} / \mathrm{kg} /$ day on weekly basis for 4 weeks \\
\hline & & Observe the patient for 1 hour after each ingestion \\
\hline & & Measure TSH and free T4 at $0,1,2$, 3and 4 hours after ingestion \\
\hline & & Measure TSH and free T4 after 1 week of the final dose \\
\hline \multirow{4}{*}{ Modified absorption test $[2,3]$} & \multirow{4}{*}{5 days } & After overnight fasting each day \\
\hline & & Administer the patient own dose in the morning for 5 consecutive days \\
\hline & & Observe the patient for 1 hour after each ingestion \\
\hline & & Measure TSH, free T4 and FT3 at day 1 and day 5 \\
\hline
\end{tabular}

As compared to a long thyroxine absorption test, the shortcomings of performing a short thyroxine absorption test are that the results can be more difficult to interpret and the applied single dose is generally much higher (usually exceeding $1000 \mathrm{mcg}$ ) and may not be well tolerated, particularly in patients with a lower weight. The absence of standardized methodology and specific cutoffs for a positive test has resulted in difficulty implementing this test in clinical practice. The complexity of its interpretation can be demonstrated by the formula proposed to calculate the percentage of absorbed thyroxine to rule out malabsorption depending on volume of distribution [9] (Table 4). One study of 23 patients with persistently elevated TSH, which compared the long and short thyroxine absorption tests, showed that $6 / 23$ patients had persistently increasing TSH after 4 weeks from baseline despite an initial rise in free $\mathrm{T} 4$ (median $>50 \%$ ) post 120 minutes ingestion and despite appropriate levothyroxine replacement using weightdetermined oral levothyroxine [7].

\section{Conclusion}

In patients with suspected 'pseudomalabsorption' of Levothyroxine the Thyroxine absorption test may aid clinicians in establishing poor compliance with objectivity and confidence. The lack of uniformity in practice or interpretation of this test may have led to it being underutilized heretofore. We report a case of pseudomalabsorption where a long thyroxine absorption test allowed us to objectively prove adequate Levothyroxine absorption, leading to reduction in Levothyroxine dosing, and restoration of euthyroidism without the need for potentially more invasive testing and without a breakdown in the therapeutic relationship with the patient. A better understanding of these tests and adoption of standard protocols is crucial for future research.

\section{References}

1. Briesacher BA, Andrade SE, Fouayzi H, Chan KA (2008) Comparison of drug adherence rates among patients with seven different medical conditions. Pharmacotherapy 28(4): 437-443. 
2. Butt MI, Gupta N, Tan HL, Waheed N (2014) Clinical Application of the Levothyroxine Absorption Test in the Diagnosis of PseudoMalabsorption. Am J Med Case Reports 2(11): 253-255.

3. Elmahi E, Vas P, Oyibo S (2013) Levothyroxine absorption testing: a 5-day (usual dose) test as an alternative to the 1-day (1000 [mu]g) test. Endocr Abstr 2013: 1-1.

4. Balla M, Jhingan RM, Rubin DJ (2015) Rapid levothyroxine absorption testing: A case series of non adherent patients. Int J Endocrinol Metab 13(4): 13-16

5. Marques R, Soares V, Marinho De Figueiredo R, Josivan Gomes Lima, Vinicius Lira da Câmara et al. (2016) Rapid Levothyroxine (Lt4) Absorption Test for Diagnosis of Lt4 Pseudomalabsorption: Case Report and Proposal of a Cutoff Point. J Endocrinol Diabetes Obes 4(1).
6. Lewandowski KC, Dąbrowska K, Komorowska-Dudek I, Lewiński A (2015) A single bolus of high dose levothyroxine (L-T4) as a test in cases of suspected poor compliance to L-T4 therapy. Thyroid Res 8(1): 16.

7. Walker JN, Shillo P, Ibbotson V, Vincent A, Karavitaki N, et al. (2015) A Thyroxine absorption test followed by weekly thyroxine administration: a method to assess non-adherence to treatment. Eur J Endocrinol 168(6): 913-917.

8. Grebe SK, Cooke RR, Ford HC, Fagerström JN, Cordwell DP, et al. (1997) Treatment of hypothyroidism with once weekly thyroxine. J Clin Endocrinol Metab 82(3): 870-875.

9. Ahmet Bahadir Ergin, A Laurence Kennedy, Manjula Gupta AH, Amir H Hamrahian (2015) the Cleveland Clinic Manual of Dynamic Endocrine Testing. Springer International Publishing 319: 13047-13047.
(C) 1 This work is licensed under Creative Submission Link: https://biomedres.us/submit-manuscript.php

\begin{tabular}{ll} 
BIOMEDICAL & Assets of Publishing with us \\
RESEARCHES & - Global archiving of articles \\
& - Immediate, unrestricted online access \\
\hline
\end{tabular}

